\title{
Growing Older in Cities: Addressing the Twin Challenges of Ageing and Urbanization
}

\author{
By Tedros Adhanom Ghebreyesus and Alana Officer
}

A t a time of unpredictable challenges for health, two trends are certain: populations around the world are ageing rapidly and we are experiencing the largest wave of urban growth in history. Demographic transition and urbanization will affect almost all aspects of society - how we live, work, and play throughout our lives and into older age.

Health is central to our experience of older age. With good health, anything becomes possible. Without it, getting out of bed can be an overwhelming challenge. For the first time in history, most people can expect to live to age 60 or beyond, although major inequalities in life expectancy persist both across and within countries. Globally, the total number of people over age 60 is set to double by 2050, rising from 1 billion to 2 billion, with 80 percent living in low- and middle-income countries.

Unfortunately, having both a long AND a healthy life are far from the reality for most people. There is very little evidence to suggest that these extra years are spent in good health. $A$ current hallmark of older age globally is the enormous diversity of health and functioning that people experience largely a consequence of the cumulative impacts of advantage or disadvantage throughout people's lives. The poorest have the worst health and the least access to the resources they need to age well. Earlier this year, when the World Health Organization analysed data for 29 million people ages 60 and older, we found that 75 percent were poor and 1 in every 7 were in poor health.

The quest for better health of older people will be won or lost in our cities. Today, over half (57 percent) of all older people live in towns and cities. By 2050, over 1 billion adults ages 60 and older will be living in urban areas. Cities and communities must find solutions to enable people to live long and healthy lives.

Cities and communities directly affect health, through barriers or incentives that affect opportunities, decisions, and behaviour. Cities and communities that are age-friendly foster healthy and active ageing through two key mechanisms:

- Promoting health and building and maintaining physical and mental capacity across the life course (e.g., by reducing air pollution, encouraging physical activity, reducing crime rates and traffic crashes, and providing quality health care); and

- Enabling people who experience a loss of capacity to continue to do the things they value (e.g., by providing appropriate assistive technologies, offering accessible public transport, modifying housing, developing safer neighborhoods, and providing long-term care).

In 2010 the World Health Organization (WHO) set up the WHO Global Network for Age-Friendly Cities and Communities. With support from 14 affiliates, including AARP, over 800 mayors in 40 countries have joined the movement and committed to making their cities and communities more age-friendly. Central to these concrete actions is the involvement of a broad range of sectors and stakeholders, including older people, with a focus on equity, intergenerational relations, and solidarity.

For example, in New York City, continued commitment by successive mayors has been vital in developing measures to improve the safety of older pedestrians in areas of the city where older people had been involved in accidents that resulted in severe injuries or fatalities. Between 2009 and 2014, more than 600 dangerous intersections were redesigned, and pedestrian fatalities among older people decreased by 21 percent. Other more recent improvements include 4,000 new transparent bus shelters that increase visibility and safety, and an additional 1,800 specially designed benches that enable older people, even with reduced mobility, to get out and about. As a result, older people have reported establishing new social ties while sitting on benches.

In Ottawa, neighbourhood walking audits and advocacy led by older citizens resulted in the passage of a new speed reduction policy, lengthened cross times at 5 busy intersections, audible pedestrian signals installed at 75 percent of all intersections, 33 new 


\section{"The quest for better health of older people} will be won or lost in our cities. Today, over half ( 57 percent) of all older people live in towns and cities. By 2050, over 1 billion adults ages 60 and older will be living in urban areas."

red-light cameras, better signage, and a citywide campaign to promote safe crosswalk usage by all road users of all ages and abilities.

In Barcelona, 200 local councils refurbish 2,000 houses a year, on average, to ensure that the most vulnerable older adults can live in a home that is accessible, safe, hygienic, and energy efficient. Porto City in Portugal is tackling older adults' social isolation and helping students find affordable accommodation by managing a programme that matches older adults willing to share their homes with students seeking accommodation. WHO's database of age-friendly practices provides a wealth of concrete examples of changes that members have made.

Health is a platform for sustainable development, and our cities and communities are vehicles for realizing the right to health. In Goals 3 and 11 of the Sustainable Development Goals ${ }^{1}$, the world has committed to "Ensure healthy lives and promote well-being for all, at all ages" and to "Make cities and human settlements inclusive, safe, resilient and sustainable." Cities and communities that foster healthy ageing are essential for people to fulfill their potential throughout their lives, for individuals and families to receive the support they need, for cities and communities to prosper, and for nations to thrive. The WHO Global Network for Age-friendly Cities and Communities is an important initiative to foster healthy ageing by:
- Inspiring change by showing what can be done and how it can be done;

- Connecting cities and communities worldwide to facilitate the exchange of information, knowledge, and experience; and

- Supporting cities and communities to find appropriate, innovative, and evidence-based solutions.

Making tangible improvements in the lives of older people, their families, and their communities is central to the Decade of Healthy Ageing (2021-2030) - the last ten years of action under the WHO Global Strategy on Ageing and Health (2016- 2030). Age-friendly cities and communities across the world will be key to achieving a healthier, safer, and fairer world for everyone, everywhere.

1. The Sustainable Development Goals are a collection of 17 global goals set by the United Nations General Assembly in 2015, which cover social and economic development issues including poverty, hunger, health, education, global warming, gender equality, water, sanitation, energy, urbanization, environment and social justice.

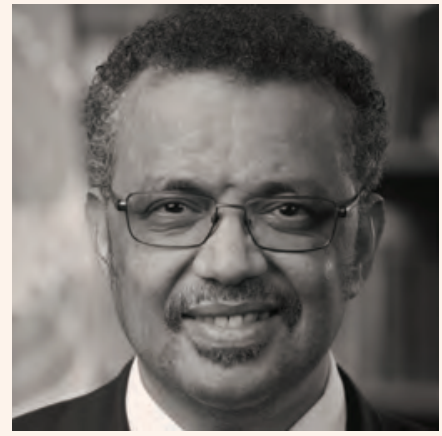

Tedros Adhanom Ghebreyesus DIRECTOR-GENERAL, WORLD HEALTH ORGANIZATION (WHO)

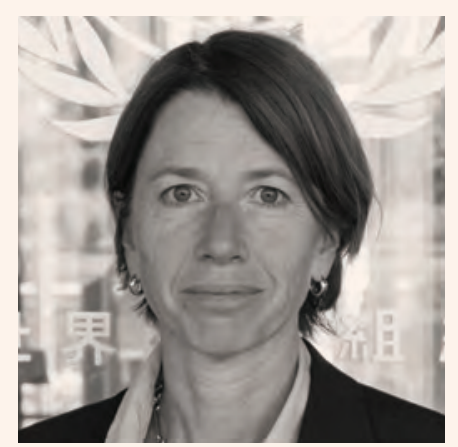

Alana Officer SENIOR HEALTH ADVISER IN THE DEPARTMENT OF AGEING AND LIFE COURSE, WORLD HEALTH ORGANIZATION (WHO) 